\section{A HUMANIZAÇÃO DA MEDICINA NO BRASIL: REFLEXÕES}

O caráter multifatorial da saúde, tão bem explicado e definido por Sérgio Arouca', expressa o quanto ainda pode ser feito na redução sustentada das doenças marcadas pelo contexto social, além de promover-se o bem-estar físico e mental da população brasileira.

A sociedade, em especial a comunidade científica, deve lutar arduamente pela universalização deste novo conceito de saúde, buscando sempre defender a necessidade de construção de uma sociedade mais igualitária e aliar os ideais políticos com a promoção da saúde.

ASaúde Pública brasileira evoluiu muito nos últimos anos, quando muitas questões sociais e estruturais foram adicionadas ao seu contexto. As Conferências Nacionais de Saúde, os Conselhos Municipais, a descentralização das ações (municipalização) e a universalização dos direitos representam excelentes conquistas do Sistema Único de Saúde(SUS).

Não obstante, o momento atual revela ainda a precariedade de investimentos em políticas intersetoriais. A estrutura do SUS ainda é centrada principalmente no modelo assistencial e o Ministério da Saúde é organizado segundo a lógica hospitalar². É necessário redefinir prioridades e discutir a substituição da Secretaria de Assistência à Saúde(SAS) e do pagamento por prestação de serviços, por um modelo que preconize um contrato global - com metas de desempenho e qualidade definidas pela população.

O Programa Saúde da Família(PSF) pode ser utilizado como uma ferramenta para reestruturar o sistema de saúde ${ }^{2}$. Cabe às equipes do PSF prestar atendimento personalizado às famílias segundo o conceito de desenvolvimento local, integral e sustentável.

Outro desafio para o século XXléa necessidade de humanização da saúde. Aadaptação do currículo médico àvisão moderna de saúde - através das novas diretrizes curriculares dos cursos de medicina no $\mathrm{Brasil}^{3}$ - representa uma importante conquista neste aspecto. Além da diversificação dos cenários de aprendizagem - incluindo treinamento junto à comunidade, em unidades básicas de saúde, ambulatórios, serviços de emergência e enfermarias de hospitais comunitários $^{3}$-, a consolidação definitiva desse novo olhar para a saúde exige também o incentivo cada vez maior de projetos naárea de medicina preventiva.

Em um país subdesenvolvido como Brasil - onde a população é numerosa e os recursos financeiros são escassos -, convém valorizar práticas alternativas de saúde, menos dispendiosas, como a fitoterapia, a acupuntura e a homeopatia.
Importa salientar ainda a necessidade de maiores investimentos em políticas de gestão participativa em saúde. A exigibilidade do direito à saúde requer que a população se aproprie de informações sobre os princípios e diretrizes do SUS. Os espaços compartilhados de controle social deverão assumir o desafio de formação de uma cultura de co-responsabilidade, pautada na concepção da saúde como bem público, direito social, e dever do Estado, incluindo governo e sociedade.

No Brasil, diferentes meios de comunicação são utilizados para difusão, à população, de conteúdos informativos sobre a saúde e o SUS ${ }^{4}$. A busca de novos canais de escuta da comunidade, entretanto, é fundamental para a consolidação do SUS como política de efetiva universalização dos direitos de cidadania, possibilitando a atuação global e precisa baseada nas reais percepções, demandas e necessidades da população.

As iniciativas voluntárias (através de projetos de extensão naárea de medicina preventiva, por exemplo) - pautadas em valores de humanização e solidariedade - promovem espaços compartilhados de atuação e englobam outros setores do governo comprometidos com a produção de saúde (ex. as universidades federais). Tais iniciativas constituem exemplos de práticas de articulação intersetorial, fundamentais para a efetiva inclusão social da população brasileira.

Frenteà reafirmação da necessidade de mudança, nós dedicamos nossas palavras à memória da construção filosófica e política que sempre esteve presente no pensamento e nos atos do sanitarista Sérgio Arouca, exemplo inestimável para estudantes de medicina que sonham e buscam seus ideais de transformar a saúde e estendê-la para toda a população brasileira.

Israel de lucena Martins Ferreira
Tiago Pessoa Tabosa e Silva tiago Pessoa tabosa e Silva

\section{Referências}

I. Arouca ASS. O dilema preventivista: contribuição para a compreensão e crítica da medicina preventiva [tese]. Campinas: Faculdade de Ciências Médicas, Universidade de Campinas; 1975.

2. Arouca ASS. RADIS entrevista Sérgio Arouca: o eterno guru da Reforma Sanitária. RADIS Comunicação em Saúde 2002:3:18-21. Disponível em: http://bvsarouca.cict.fiocruz.br. [citado 23 dez. 2006].

3. Martins MA. Ensino médico [editorial]. Rev Assoc Med Bras. 2006;52(5):282-2

4. Rivera FJU, Artmann E. Planejamento e gestão em saúde: flexibilidade metodológica e agir comunicativo. Ciênc Saúde Coletiva. 1999;4(2):355-65. 